\title{
Individual differences in figural aftereffect potency: Aftereffect trace vs immediate stimulus context as a determiner of perception
}

\author{
LUDWIG IMMERGLUCK ${ }^{1}$ \\ SAN FRANCISCO STATE COLLEGE, CALIFORNIA
}

When, given the same stimulus pattern, the direction of a perceptual response can be determined by either the strength of an aftereffect trace or by an immediately present stimulus context, field-independent $S s$ responded in accordance with the aftereffect trace, while field-dependent $S s^{\prime}$ perceptions were influenced by the immediately present stimulus context. The data at hand continue to demonstrate significant differences in aftereffect potency between field-independent and field-dependent Ss.

When after continuous visual fixation of a curved line an objectively straight line is viewed, it will typically appear to be curved in a direction opposite to that of the previously inspected line. But perceived curvature of an objectively straight line can also be brought about by embedding the line in a certain contextual pattern such as in the case of the well known Hering's illusion, a modified version of which is shown in Fig. 1. Unlike the aftereffect phenomenon which depends on a temporal separation between the Inspection figure and the Test figure, the illusion based distortion is brought on by an interaction of simultaneously present stimulus patterns. Here the effect is not presumed to be generated by altered intraorganic states but rather by factors inherent in the immediately present stimulus conditions themselves, by the contiguous context.

If, now, instead of utilizing the usual sole straight line as the Test figure in the aftereffect sequence, the appropriate line in Hering's illusion (which is, of course, also objectively straight) is employed as the Test figure, the differential potency between "trace residue" aftereffect and context based distortion may be assessed. To be more specific, if the Inspection figure is comprised of a line curved in the same direction as that experienced in Hering's illusion, then the aftereffect, bending, as it were, the Test line in the opposite direction, should counteract the illusory pull and, in effect, result in more veridical perception of the Test line embedded in Hering's illusion. If, on the other hand, the immediately present stimulus context is more potent, then the illusion should counteract any trace residue, and the embedded Test line should continue to be perceived as curved in the direction identical to that of the previously fixated Inspection line.

The present study seeks to explore the differential potency between an aftereffect trace residue and stimulus context in a manner outlined above, but in a setting which permits an assessment of the effects of individual differences in figural aftereffect strength and of related differences in perceptual measures of field dependence.

In a series of recent studies (Immergluck, 1966a, $1966 \mathrm{~b}, 1966 \mathrm{c})$ it was shown that field-independent Ss (assessed by the Rod and Frame Test) exhibited more potent aftereffects than did field-dependent ones in whom apparently the residual effects of an originally fixated visual stimulus are more readily obliterated by subsequently viewed new and immediately present stimuli (e.g., the Test figure).

Extending, then, these observed intrasubject differences in figural aftereffect performance to the present investigation, it seems reasonable to assume that: (1) Ss who exhibit potent aftereffects (i.e., who are demonstrably field-independent) should, following fixation of an appropriate curved stimulus line, perceive the Hering illusion line as "straight"; and (2) Ss who demonstrate weak aftereffect trace residues (i.e., fielddependent Ss) should be relatively unaffected by the fixated Inspection figure and continue to experience the apparent curvature in Hering's illusion.

Method

The S groups, college students ranging from 19 to 23 years, were selected on the basis of their performance on the Rod and Frame Test in a manner identical to that in the previously reported studies (Immergluck, $1966 \mathrm{a}, 1966 \mathrm{~b}, 1966 \mathrm{c})$, with the final establishment of 30 field-independent and 26 field-dependent Ss. In
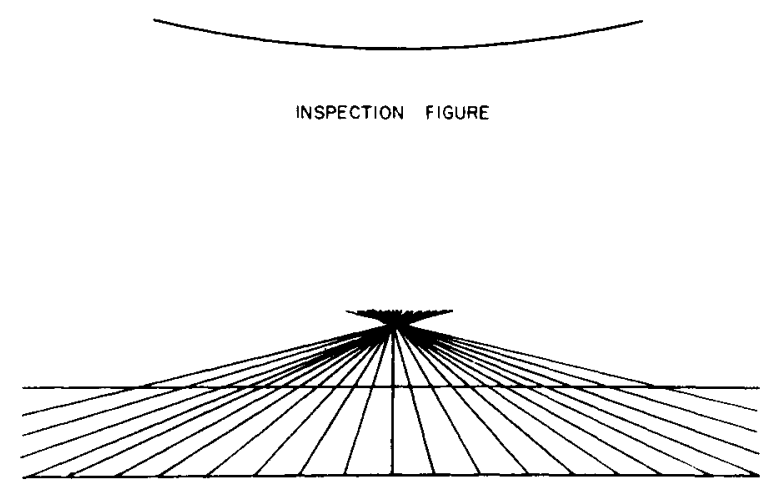

TEST FIGURE

Fig. 1. The curved line Inspection Figure measures $11.5 \mathrm{~cm}$ with a radius of $19 \mathrm{~cm}$. The modified Hering illusion Test Figure horizontal line is $16.5 \mathrm{~cm}$ long. 
Table 1. A comparison between field-independent and field-depend it Ss in figural aftereffect performance.

\begin{tabular}{lcccc}
\multicolumn{1}{c}{ Subjects } & N & Aftereffect & No Aftereffect & P \\
\hline Field-independent & 30 & 23 & 7 & \\
Field-dependent & 26 & 5 & 21 & $<.001$ \\
\hline
\end{tabular}

order to assess once again the relationship between measures of field dependence and aftereffect potency, all Ss were exposed to the same size displacement figural aftereffect task employed in the previously cited studies (ibid).

After a rest period of $10 \mathrm{~min}$, all Ss (tested in individual sessions) were presented with the curved line I Figure (Fig. 1) and asked to fixate it steadily in the center. Following an inspection time of $30 \mathrm{sec}$, the Hering illusion $\mathrm{T}$ Figure (Fig. 1) was immediately presented, and the $\mathrm{S}$ was asked to specify the appropriate Test line as "curved" or "straight." In order to ascertain more unequivocally whether the reported curvature adhered to the direction implied by the Hering illusion, all Ss who perceived the Testlineas "curved" were also required to specify direction of curvature. (The responses of all Ss indicated that the perceived curvature was in line with the Hering illusion.)

In order to rule out possible differences between field-independent and field-dependent Ss in their ability to counteract the Hering illusion apart from those produced by aftereffect traces (particularly since such differences have been previously reported; Crutchfield et al, 1958; Immergluck, 1966; McGurk, 1965), two different $\mathrm{S}$ groups, comprised of 25 field-independent and 25 field-dependent Ss were asked to respond to the identical Hering illusion without previous exposure to the curved line aftereffect task. The results are summarized in Table 3 and show the ubiquitous potency of this particular illusion and no differences between these two S groups.

\section{Results and Discussion}

The present results (Table 1) show clearly that field-

Table 2. A comparison between field-independent and field-dependent Ss in their responses to the Test line in Hering's illusion following fixation of the I Figure. The "Straight" column indicates the number of Ss who perceived the Test line as straight, and the "Curved" column the number of Ss who perceived the Test line as curved.

\begin{tabular}{lrrrr}
\multicolumn{1}{c}{ Subjects } & N & Straight & Curved & P \\
\hline Field-independent & 30 & 22 & 8 & $<.001$ \\
Field-dependent & 26 & 6 & 20 & \\
\hline
\end{tabular}

Table 3. A comparison between field-independent and field-dependent Ss in their responses to Hering's illusion without prior exposure to the figural aftereffect task.

\begin{tabular}{llcc}
\multicolumn{1}{c}{ Subjects } & N & Straight & Curved \\
\hline Field-independent & 25 & 3 & 22 \\
Field-dependent & 25 & 2 & 23 \\
\hline
\end{tabular}

independent Ss exhibit more potent aftereffects than field-dependent ones $\left(\chi^{2}=18.37, p<0.001\right)$ and (cf. Table 2), given a stimulus situation in which an immediately present field context is juxtaposed against an aftereffect trace residue, will perform perceptually in accordance with the trace residue. For field-dependent Ss, on the other hand, the immediately present stimulus context proved to be the more potent determiner of their perceptual response $\left(X^{2}=14.07\right.$, $p<0.001$ ). Inspection of Tables 2 and 3 permits direct comparison of perceptual responses to Hering's illusion between comparable $\mathrm{S}$ groups with and without prior exposure to the curved line aftereffect task and shows clearly that such prior visual fixation has an effect on only the field-independent $S$ group. It may also be of interest to note that the found relationship between measures of field independence and aftereffect strength is underscored by the fact that two different aftereffect tasks, composed of different kinds of Inspection figures, were employed in the present investigation, both yielding very comparable results (cf. Tables 1 and 2).

The data at hand continue to demonstrate significant differences in visual aftereffect potency between fieldindependent and field-dependent Ss and invite further explorations of the effects of such differences in other diverse perceptual situations.

References

CRUTCHFIELD, R. S., WOODWORTH, D. G., \& ALBRECHT, R. C. Perceptual performance and the effective person. Personnel Lab. Rep., WADC-TN-58-60 ASTIA doc. No. 131039, Lackland AFB, Texas, 1958.

IMMERGLUCK, L. Visual figural after-effect and field-dependence. Psychon. Sci., 1966a, 4, 219-220.

IMMERGLUCK, L. Figural after-effects, rate of "figure-ground" reversal, and field-dependence. Psychon. Sci, 1966b, 6, 45-46.

IMMERGLUCK, L. Resistance to an optical illusion, figural aftereffects, and field-dependence. Psychon. Sci., 1966c, 6, 281-282. McGURK, E. Susceptability to visual illusions. J. Psychol, 1965, 61, 127-143.

WITKIN, H. A., LEWIS, H. B., HERTZMAN, M., MACHOVER, K., MEISSNER, P. B., \& WAPNER, S. Personality through perception. New York: Harper, 1954.

Note

1. This research was supported by a faculty research fund, San Francisco State College, under the auspices of a National Science Foundation Institutional Grant. 